\title{
Intercept-Reactant Method for the Determination of Aromatic Amines in Mainstream Tobacco Smoke
}

\author{
by \\ Gernot:Grimmer, Dietmar Schneider, \\ Klaus-Werner Naujack, Gerhard Dettbarn, Jürgen Jacob \\ Biochemisches Institut für Umweltcarcinogene, \\ Lurup 4, \\ D-22927 Großhansdorf
}

Dedicated to Prof. Dr. Dres. b.c. Herbert Oelscbläger on the occasion of bis $75 t b$ birtbday

\section{SUMMARY}

A method for the determination of aromatic amines in mainstream smoke of mechanically smoked cigarettes has been developed. The fast reaction of aromatic amines with other smoke constituents formed during the combustion process can be significantly reduced by the addition of an excess of p-toluidine to the acidic collecting solution. From this point the p-toluidine as intercept reactant immediately stabilizes the originally formed amines and results in high recovery rates.

The method allows the gas chromatographic determination of aniline, $\sigma$ and m-toluidine, 1- and 2-aminonaphthalene, 2- and 4-aminobiphenyl, 1-, 2- and 4-aminofluorene, 3-aminofluoranthene, 1-aminopyrene and $6-$ aminochrysene in the mainstream smoke of a single cigarette. $\mathrm{d}_{5}$-Aniline, $\mathrm{d}_{7}$-2-aminonaphthalene, $\mathrm{d}_{9}-4$ aminobiphenyl as well as fluoranthene and chrysene were used as internal standards.

By this new method, $21 \mathrm{ng}$ of 2-aminonaphthalene and about 3,6 $\mathrm{ng}$ of 4-aminobiphenyl have been detected in the mainstream smoke of a common blend filter cigarette. As expected, these contents were higher in cigarettes manufactured from alkaline tobacco.

\footnotetext{
4 Received: 21th October 1994 - accepted: 20th April 1995
}

\section{ZUSAMMENFASSUNG}

Es wurde ein GC-MS-Bestimmungsvervahren für aromatische Amine in Hauptstromrauch maschinell abgerauchter Zigaretten entwickelt. Durch Zugabe von überschüssigem p-Toluidin in die saure Auffanglösung konnte die schnelle Reaktion der durch den Rauchvorgang gebildeten aromatischen Amine mit weiteren Rauchbestandteilen wesentlich verringert werden. Die Verwendung von p-Toluidin als Intercept-Reaktand stabilisiert die ursprünglich gebildete Aminmasse und ermöglicht hohe Wiederfindungsraten.

Die Methode erlaubt die gaschromatographische Bestimmung von Anilin, or, m-, p-Toluidin, 1- und 2Aminonaphthalin, 2- und 4-Aminobiphenyl, 1-, 2- und 4Aminofluoren, 3-Aminofluoranthen, 1-Aminopyren und 6-Aminochrysen im Hauptstromrauch einer einzelnen Zigarette. Als innerer Standard wurde $d_{5}$-Anilin, $d_{7}-2-$ Aminonaphthalin, $\mathrm{d}_{9}$-4-Aminobiphenyl sowie Fluoranthen und Chrysen verwendet.

Im Hauptstromrauch einer markthäufigen BlendFilterzigarette wurde bei einer Berücksichtigung der Wiederfindungsraten ein Gehalt von 21 ng 2Aminonaphthalin sowie etwa 3,6 ng 4Aminobiphenyl ermittelt. Erwartungsgemäß lagen die Gehalte bei Zigaretten aus alkalischen Tabaken höher. 


\section{RESUME}

Une méthode GC-MS a été mis au point pour doser les amines aromatiques dans la fumée du courant principal captée après fumage méchanique des cigarettes. La réaction rapide des amines aromatiques, qui se sont formées au cours de la combustion, avec d'autres composantes de la fumée pouvait être ralentie substantiellement en joignant à la solution collectrice acide du p-toluidine excédentaire. L'utilisation du p-toluidine comme réactant d'interception stabilise immédiatement les amines formées initialement et conduit à des taux de rétablissement élevés.

La méthode permet de doser au moyen de la chromatographie en phase gazeuse dans la fumée du courant principal des cigarettes la teneur en aniline, $o$-, $\mathrm{m}$-, p-toluidine, 1- et 2-aminonaphtaline, 2- et 4 aminobiphényle, 1-, 2- et 4-aminofluorène, 3-aminofluorantène, 1-aminopyrène, et 6-aminochrysène. $\mathrm{L}_{2} \mathrm{~d}_{5}$-aniline, la $\mathrm{d}_{7}$-2-aminonaphthaline, le $\mathrm{d}_{9}$-4-aminobiphényle ainsi que le fluoranthène et le chrysène étaient utilisés comme standard interne.

Grâce à cette nouvelle technique, 21 ng de 2-aminonaphthaline et environ 3,6 ng de 4-aminobiphényle pouvaient être déterminés dans la fumée principale d'une cigarette de mélange habituel. Comme prévu, la teneur en ces substances était plus élevée dans les tabacs alcalins.

\section{INTRODUCTION}

The objective of this project was to develop a precise analysis for the determination of mainstream tobacco smoke constituents such as aniline, $\alpha, \mathrm{m}$ - and p-toluidine, 1- and 2-aminonaphthalene, 2- and 4-aminobiphenyl, 1-, 2- and 4-aminofluorene, 3-aminofluoranthene, 1-aminopyrene and 6-aminochrysene. Preliminary investigations indicated that aromatic amines formed during the combustion process are rapidly decomposed or undergo further reactions with other smoke constituents. The amount (mass) of the pyrolytically formed aromatic amines decreases according to their individual reactivities over time in the presence of other reactive smoke constituents.

Hence, different yields are found for the various aromatic amines at the time of derivatization of free amines to the corresponding pentafluopropionates. Since the reaction kinetics are expected to be even more complex on a collecting filter, none was used. The mechanically produced mainstream cigarette smoke was collected by passing through several subsequent wash bottles. This also allowed us to measure the decomposition kinetics of the various amines in a homogenous phase. In order to get an optimum collection of the gaseous and particulate constituents, the smoke was passed through a glass frit into the collecting liquid (1 $\mathrm{N}$ phosphoric acid).

As a consequence of these complexities, the mass spectrometric quantitation of the gas chromatographically separated amines consisted only of their amount remaining which were left between the pyrolytic formation and the derivatization of the amino group. The decomposition of the amines after their formation and the entrance into the acidic collecting liquid cannot be measured, whereas further losses by decomposition reactions or evaporation during the clean-up procedure may be calculated by comparison with initially added internal standards such as the corresponding deuterated compounds.

PAILER et al. (1) reported in 1967 the occurrence of 1aminonaphthalene and an incompletely characterized aminofluorene. Shortly after this, MASUDA and HOFFMANN (2) isolated and identified 1- and 2-aminonaphthalene from the mainstream condensate of 12.000 cigarettes. They also described in their paper an isotope dilution method for the quantitative determination of these amines in the condensate of 300 US-filter cigarettes $(85 \mathrm{~mm})$ separately smoked under standard conditions. The amounts reported - $27 \mathrm{ng}$ of 1-aminonaphthalene and 22 ng of 2-aminonaphthalene/cigarette - could not be confirmed in later publications of this group.

About 30 additional aromatic amines were identified in main- and sidestream tobacco smoke by SCHMELTZ and HofmmanN (3) and Patrianaros and HofmManN (4). Concentrations of $4.3 \mathrm{ng}$ of 1-aminonaphthalene and 1.0 ng of 2-aminonaphthalene per cigarette were reported to be present in the mainstream smoke of $85 \mathrm{~mm}$ USnonfilter cigarettes: Similar concentrations of these amines (2.5 and $1.7 \mathrm{ng} / \mathrm{cig}$.) were found in French $70 \mathrm{~mm}$ nonfilter cigarettes. Comparable concentrations have been reported in filter cigarettes such as Gauloise, Nazionali, Marlboro, Camel, MS, MS mild and MS light by PIERACCINI et al. (5) and by LUCERI et al. (6). A nonfilter Gauloise, however, exhibited significantly higher concentrations with $16.7 \mathrm{ng}$ of 1-aminonaphthalene and $4.6 \mathrm{ng}$ of 2-aminonaphthalene per cigarette. The amine concentrations reported for these cigarettes may be in error, since no labeled internal standards were used for this determination. Furthermore, in the pre-extraction of the acidic solution, by diethyl ether, used for separation of the smoke a large proportion of aromatic amines with 2 or more rings may be lost.

To overcome these problems we have attempted to carry out the enrichment of the amine fraction from the mainstream tobacco smoke condensate as quickly as possible and to reduce the decomposition of amines during clean-up by the addition of lange amounts of $p$ toluidine to the phosphoric acid-containing solution in the collection wash bottles. 
In order to accurately determine the aromatic amines occurring in mainstream tobacco smoke, a method for the enrichment of primary and secondary amines in a single fraction has been developed.

\section{DESCRIPTION OF THE METHOD}

The cigarettes used were conditioned $(60 \%$ atmospheric humidity) prior to mechanically smoking according to DIN 10240T1 (4.4.91).

\section{Collection method}

In order to collect the gaseous and particulate phase of the mainstream smoke, a single cigarette was smoked according to the DIN-Norm by using a RM1/GR 58 Borgwaldt smoking machine and the mainstream smoke passed into two sequentially arranged wash bottles (Figure 1). For a better distribution of the smoke it is recommended passing the gas stream through a glass frit (G1) into the mixture of $1 \mathrm{~N}$ phosphoric acid (puriss.) and methanol $(1: 1 ; 50 \mathrm{~mL})$ used for the collection. The collection solution was spiked with 10 or $250 \mu \mathrm{g}$ ptoluidine, and $\mathrm{d}_{5}$-aniline, $\mathrm{d}_{7}-2$-aminonaphthalene and $\mathrm{d}_{9}-4$ aminobiphenyl were added as internal standards. After the smoke of one cigarette had passed through the solution, the latter was adjusted to $\mathrm{pH} 8$ by the addition of sodium hydrogen carbonate and then is extracted twice with $50 \mathrm{~mL}$ aliquots of benzene.

The benzene phase was evaporated to about $2 \mathrm{~mL}$ (rotatory evaporator, $200 \mathrm{hPa}, 40^{\circ} \mathrm{C}$ water bath) and $5 \mathrm{~mL}$ methanol added.

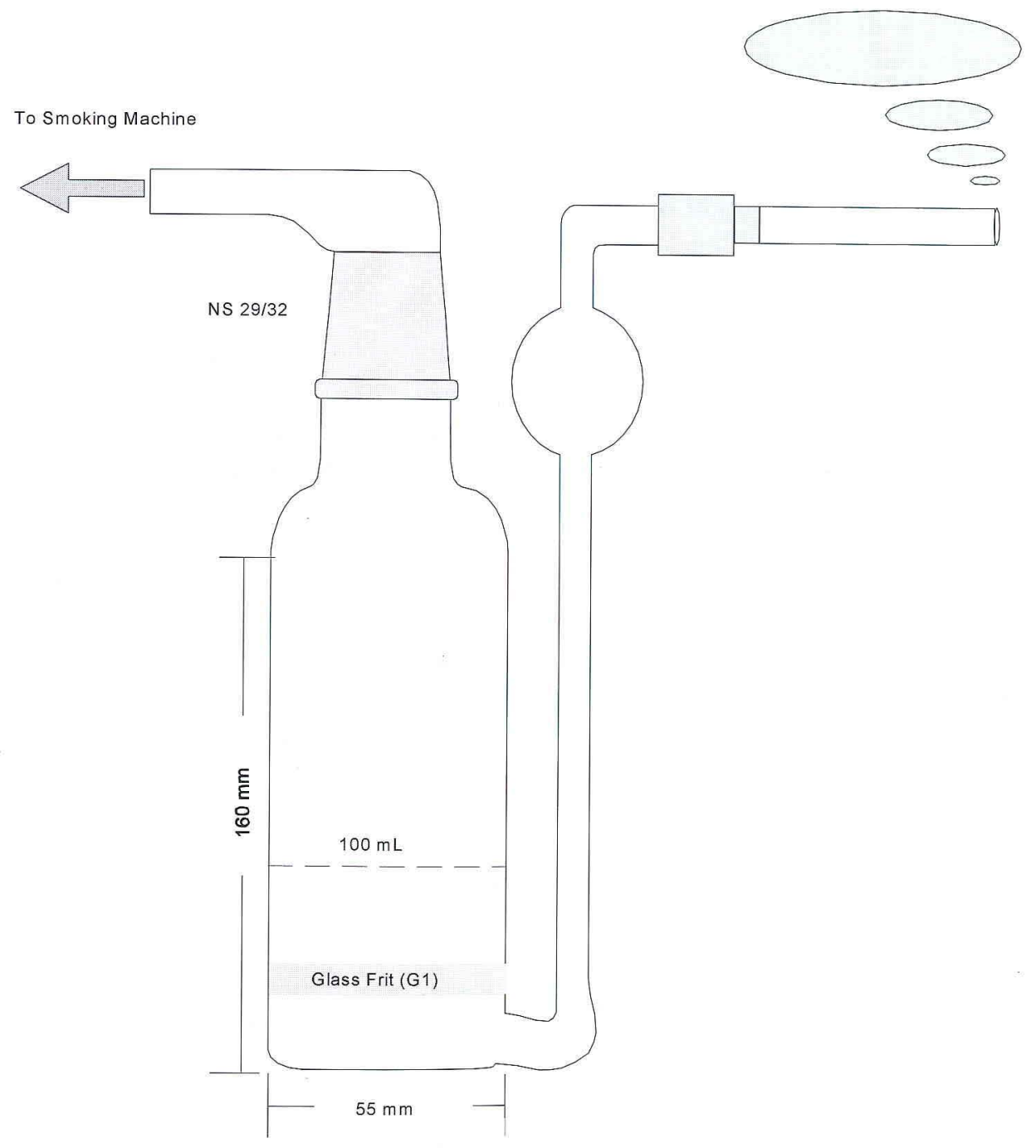

Figure. 1.

Device for the collection of aromatic amines from tobacco smoke (wash bottle). 
Ion exchanger

$0.5 \mathrm{~g}$ Bakerbond aromatic sulfonic acid was placed between two teflon frits in a glass cartridge $(8 \mathrm{~mL}$, Bakerbond SPE-system) and activated with $5 \mathrm{~mL} 1 \mathrm{~N}$ phosphoric acid. The cartridge was pre-washed with 30 $\mathrm{mL}$ methanol. The amine solution obtained by the above extraction was passed through the column which was then washed with $30 \mathrm{~mL}$ methanol. Subsequently, the amines were eluted with $20 \mathrm{~mL}$ of a $0.2 \mathrm{M}$ ammonium acetate solution in $90 \%$ methanol. The eluate was diluted with $30 \mathrm{~mL}$ water and the amines extracted with $50 \mathrm{~mL}$ benzene. Fluoranthene (e.g. $1000 \mathrm{ng}$ ) was added as a fourth internal standard.

\section{Acylation with pentafluoropropionylimidazol (PFPl)}

The benzene extract was evaporated to $2 \mathrm{~mL}$ (rotatory evaporator, $200 \mathrm{hPa}, 40^{\circ} \mathrm{C}$ water bath), transferred to a $3 \mathrm{~mL}$ pointed flask, evaporated to about $0.5 \mathrm{~mL}$, and 50 $\mu \mathrm{L}$ of a triethylamine solution ( $0.5 \mathrm{M}$ in benzene) added. For acylation, $50 \mu \mathrm{L}$ pentafluopropionyl-imidazol (PFPI) was added and the mixture maintained in a stoppered flask at $50^{\circ} \mathrm{C}$ for $15 \mathrm{~min}$ in a sandbath. The reaction mixture was then cooled in an icebath, the excess of PFPI extracted with water $(0.5 \mathrm{~mL})$ and centrifuged to improve phase separation.

The benzene phase was then diluted with $3 \mathrm{~mL}$ methanol and passed through a second ion exchange column (see above) which was pre-washed with $30 \mathrm{~mL}$ methanol. Amines were eluted with $2 \times 50 \mathrm{~mL}$ benzene and the latter evaporated to a small volume. This second ion exchange column step can be eliminated when GC/MS is used for the analysis.

\section{Florisil column}

$1 \mathrm{~g}$ Florisil (Merck, 15\% water) was placed between 2 teflon frits of a glass cartridge ( $8 \mathrm{~mL}$, Baker SPE system) and pre-washed. The small volume of the acylation procedure was placed on the column and eluted with 20 $\mathrm{mL}$ benzene. The eluate was evaporated to $2 \mathrm{~mL}$, transferred to a $3 \mathrm{~mL}$ pointed flask, evaporated to $50 \mu \mathrm{L}$ and $1 \mu \mathrm{L}$ of it injected into the gas chromatograph. Flame ionisation detection (FID) and/or GC/MS data were used for the evaluation.

\section{Gas chromatographic conditions:}

Delsi Di 700 , FID or Hewlett-Packard, HP 5890, Series II plus;

FS-capillary Nordion SE-54, $25 \mathrm{~m} \times 0,32 \mathrm{~mm}$ I.D.;

On-column injection at $72{ }^{\circ} \mathrm{C}$;
$12 \min 85^{\circ} \mathrm{C}$, then

$$
\begin{aligned}
& 85-140^{\circ} \mathrm{C} \text { with } 10^{\circ} \mathrm{C} / \mathrm{min} \text {; } \\
& 140.280^{\circ} \mathrm{C} \text { with } 4^{\circ} \mathrm{C} / \mathrm{min} \text {; }
\end{aligned}
$$

Evaluation: Trivector Trilab 2000.

Because of their low boiling points and the extreme excess of p-toluidine the evaluation of aniline, $\mathrm{o}, \mathrm{m}$ - and p-toluidine required chromatographic separation by pressure-programmed GC and a mass-selective determination via deuterated standards.

\section{Mass spectrometric conditions:}

HP 5890/II with MSD 5972;

FS-capillary HP-5MS, $30 \mathrm{~m} \times 0,25 \mathrm{~mm}$ I.D;

Splitless injection at $250^{\circ} \mathrm{C}$

$2 \min 56^{\circ} \mathrm{C}$, then

$$
\begin{aligned}
& 56^{\circ}-140^{\circ} \mathrm{C} \text { with } 10^{\circ} \mathrm{C} / \mathrm{min} \text {; } \\
& 140^{\circ}-270^{\circ} \mathrm{C} \text { with } 6^{\circ} \mathrm{C} / \mathrm{min} \text {; } \\
& 270^{\circ}-290^{\circ} \mathrm{C} \text { with } 4^{\circ} \mathrm{C} / \mathrm{min} \text {; }
\end{aligned}
$$

Evaluation: single ion monitoring quantitation by HP G1034C version C.02.0.

A schematic presentation of the clean-up along with a GC-MS chromatogram (SIM-detection) of the amine fraction enriched from tobacco smoke condensate is given in Figures 2 and 3.

\section{Smoking of 1 clgarette}

m.s. in $100 \mathrm{~mL} 0.5 \mathrm{~N} \mathrm{H}_{3} \mathrm{PO}_{4} / \mathrm{MeOH} 1: 1$

+ 1.S.: d,-2-Aminonaphthalene, $d_{2}$-Anline, d,-4-Aminoblphenyl

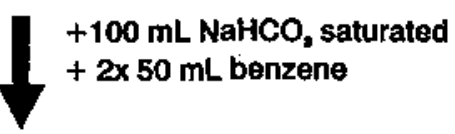

Ion exchanger Bakerbond $\mathrm{SO}, \mathrm{H}(0.5 \mathrm{~g})$

$20 \mathrm{~mL} 0.2 \mathrm{M} \mathrm{CH}_{3} \mathrm{COONH}_{4}$ in $90 \% \mathrm{MeOH}$

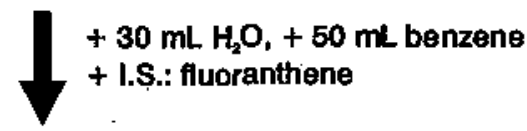

\section{Acylation with PFPI}

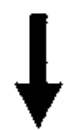

Benzene solution $(100 \mathrm{~mL})$

$f$ to $5 \mathrm{~mL}$ by evaporation

Purlfication on Florisil(1 g; 15\% $\left.\mathrm{H}_{2} \mathrm{O}\right)$ $30 \mathrm{~mL}$ benzene

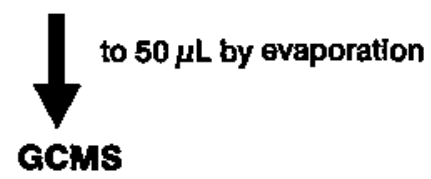

Figure. 2.

Scheme of the determination of aromatlc amines In mainstream clgarette smoke. 


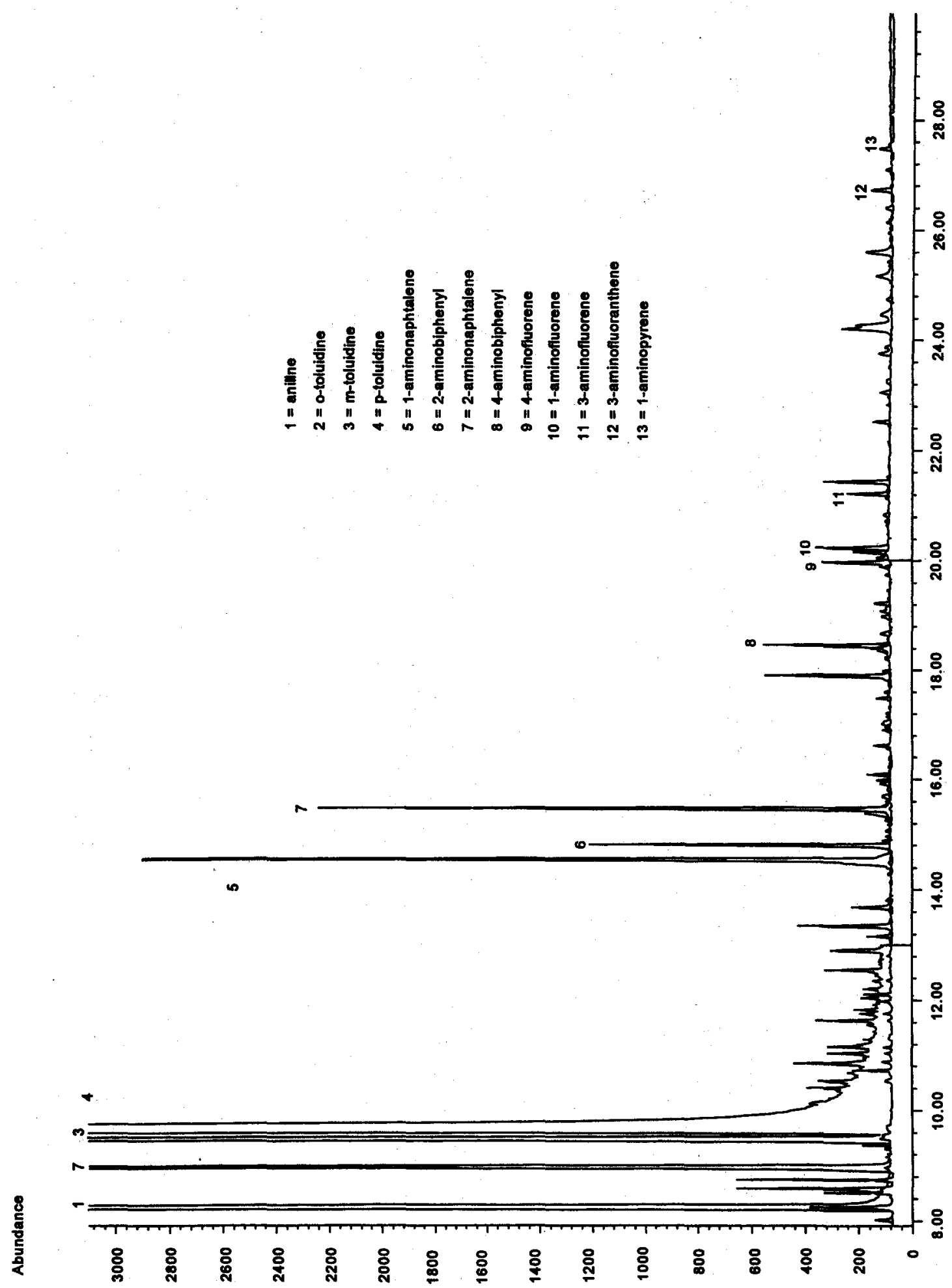

Figure 3.

GC/MS (SIM mode) of aromatic amines in mainstream tobacco smoke (for condition see: 'Description of the Method).

1 = aniline; 2 = o-toluidine; $3=$ m-toluidine; $4=$ p-toluidine; $5=1$-aminonaphthalene; $6=2$-aminobiphenyl; $7=2$ aminonaphthalene; $8=4$-aminobiphenyl; $9=4$-aminofluorene; $10=1$-aminofluorene; $11=2$-aminofluorene; $12=3$ aminofluoranthene; $13=1$-aminopyrene. 


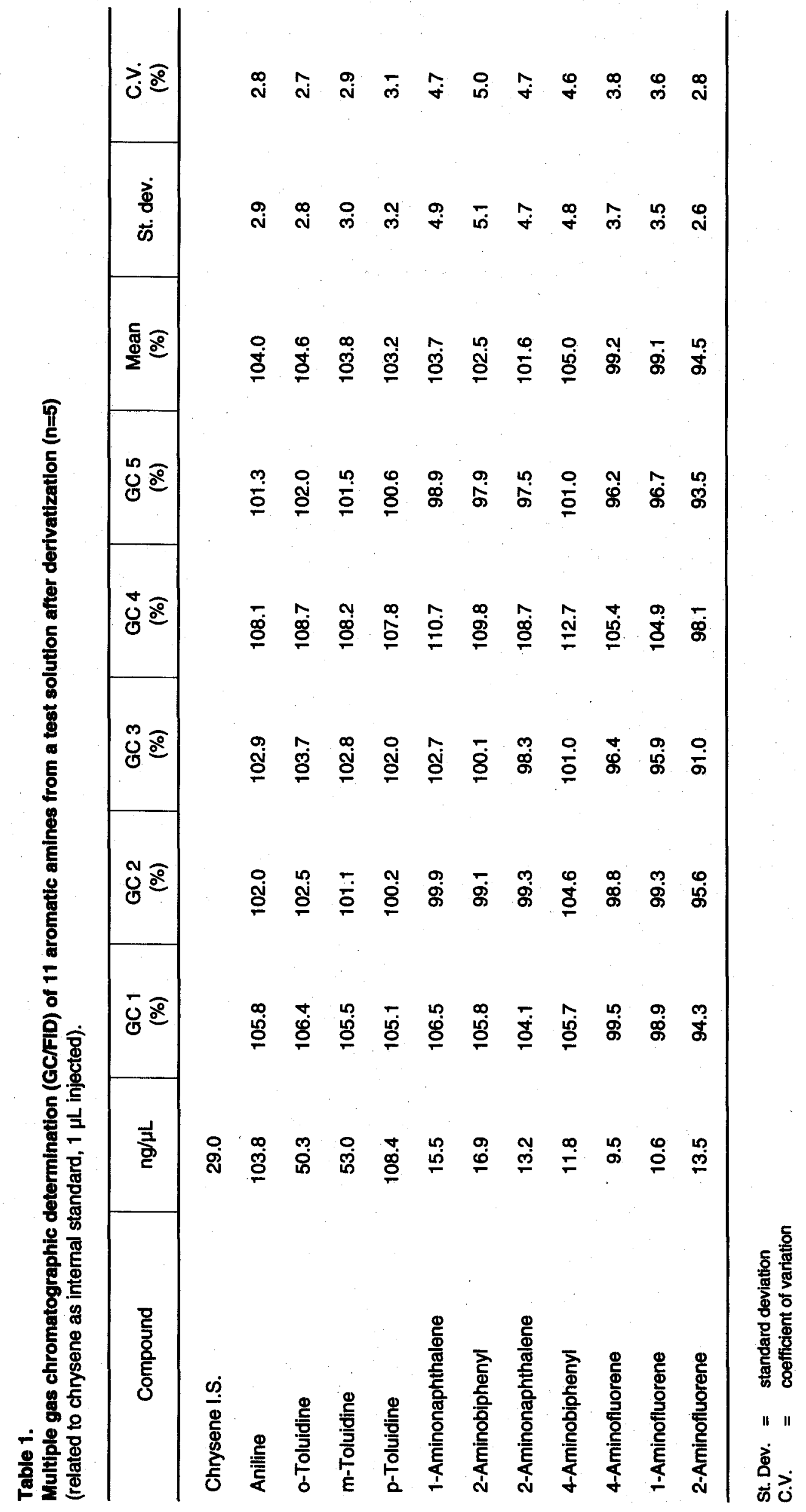




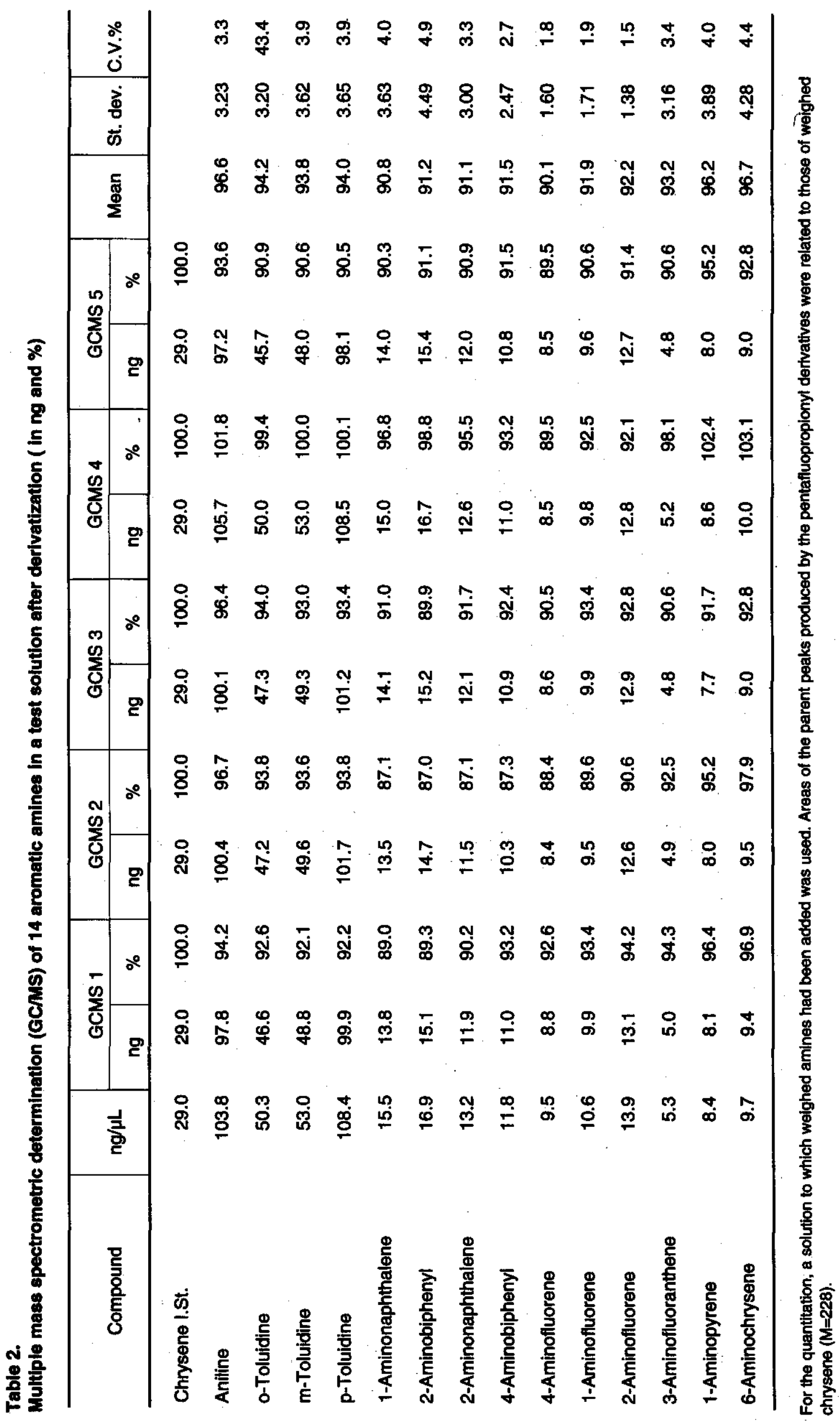




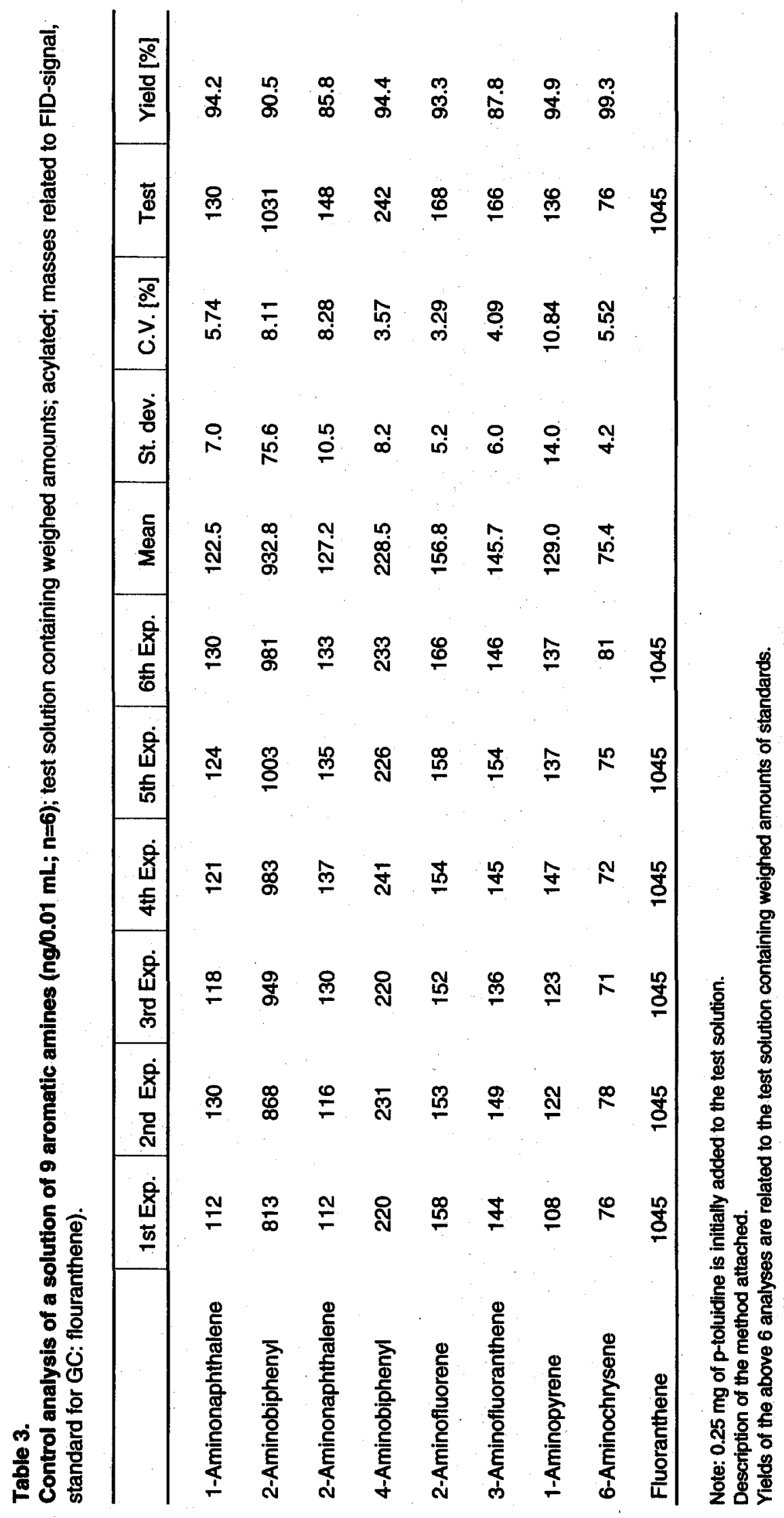


Table 4.

Simulation experiment smoklng 3 cigarettes with 7 puffs $(35 \mathrm{~mL} / \mathrm{mln})$ corresponding to $3 \times 7 \times 35 \mathrm{~mL}$ air (control).

\begin{tabular}{|c|c|c|c|c|c|c|c|}
\hline & \multirow{2}{*}{$\begin{array}{c}\text { Acylation test } \\
\mathrm{ng}\end{array}$} & \multicolumn{2}{|c|}{ 1st Wash bottle } & \multicolumn{2}{|c|}{ 2nd Wash bottle } & \multicolumn{2}{|c|}{ 3rd Wash bottle } \\
\hline & & ng & $\%$ & $\mathrm{ng}$ & $\%$ & $\mathrm{ng}$ & $\%$ \\
\hline Aniline & 710 & 411 & 57.9 & 424 & 59.7 & 375 & 52.8 \\
\hline o-Toluidine & 669 & 507 & 75.8 & 545 & 81.5 & 494 & 73.8 \\
\hline m-Toluidine & 615 & 435 & 70.7 & 480 & 78.0 & 440 & 71.6 \\
\hline p-Toluidine & 607 & 416 & 68.5 & 440 & 72.5 & 414 & 68.2 \\
\hline 1-Aminonaphthalene & 686 & 549 & 80.0 & 613 & 89.4 & 594 & 86.6 \\
\hline 2-Aminobiphenyl & 1081 & 973 & 90.0 & 1039 & 96.1 & 1035 & 95.7 \\
\hline 2-Aminonaphthalene & 700 & 593 & 84.7 & 635 & 90.7 & 594 & 84.9 \\
\hline 4-Aminobiphenyl & 871 & 735 & 84.3 & 814 & 93.5 & 770 & 88.4 \\
\hline 2-Aminofluorene & 797 & 593 & 74.4 & 661 & 82.9 & 641 & 80.4 \\
\hline 3-Aminofluoranthene & 817 & 647 & 79.2 & 698 & 85.2 & 665 & 81.1 \\
\hline 1-Aminopyrene & 692 & 609 & 88.0 & 638 & 92.2 & 620 & 89.6 \\
\hline 6-Aminochrysene & 456 & 391 & 85.7 & 444 & 97.4 & 441 & 96.7 \\
\hline
\end{tabular}

I.S. = fluoranthene (1045 ng)

Note : $\quad$ Each wash bottle contained 12 aromatic amines added to a mixture of $1 \mathrm{~N}$ phosphoric acid/methanol (50 mL $7+3)$

\section{Analytical controls}

To check the purity of the reference compounds, they were analyzed for contaminants prior to and after derivatization with pentafluopropionylimidazol. Table 1 presents a correlation between sample weights of the non-derivatized amines to the FID-signal areas of their corresponding pentafluopropionates setting the chrysene signal area to $100 \%$ (purity of chrysene $99.2 \%$ ). Surprisingly, weighings of the free amines corresponded to the FID-signal areas of the derivatized compounds and to that of chrysene without correction factors, although the derivatives contain 3 carbon atoms more. Obviously, the carbon atoms of the pentafluopropionyl residue are not detected. Therefore, yields have been calculated using this assumption and related to chrysene. Coefficients of variation of the reproducibility were found to be between $2.7 \%$ and $5 \%$.

The reproducibility of the mass spectrometric quantitation of a mixture of 14 pentafluopropionyl-amines and chrysene are presented in Table 2 . Signal areas of the parent peaks in the single ion detection mode (SIM) have been evaluated by comparison with a calibration solution ( 2 calibration points).
Coefficients of variation for five replicates were between 1.5 and $4.9 \%$, similar to those evaluated by FID.

To determine the repeatability of the entire enrichment procedure, the yields of nine known aromatic amines were determined. Yields have been calculated on the basis of fluoranthene added to the enriched fraction prior to gas chromatographic evaluation (FID).

Recoveries of the higher boiling amines were $86 \%$ to $95 \%$ in a replicate analysis including all enrichment and derivatization steps, whereas the yield of aniline was unsatisfactory. An exact determination of aniline and the toluidines is only possibly by using deuterated standards. In order to measure the influence of the presence of oxygen on the recovery of amines during clean-up, a smoking process has been simulated by passing air in the smoking regime of 3 cigarettes (7 puffs of $35 \mathrm{~mL}$ with 3 repetitions) using the smoking machine. The recovery of $>80 \%$ for the higher boiling amines and rates of 52.8 $59.7 \%$ for aniline could be confirmed for the workup of the solution (all steps; addition of fluoranthene prior to GC). As expected, evaporation losses during workup were less for toluidines (b.p. about $210^{\circ} \mathrm{C}$ ) than for aniline (b.p. $184{ }^{\circ} \mathrm{C}$ ). Results of this simulation experiment are presented in Table 4. 
Recoveries of aromatic amines with 2 to 4 aromatic rings for the multistep enrichment were satisfactory. The workup of cigarette smoke results in a very pure fraction of mainstream aromatic amines. This was confirmed by a mass spectrometric evaluation of the fraction, carried out during a later investigation.

\section{Testing of the sampling device}

The mainstream smoke of a mechanically smoked cigarette was passed into two wash bottles arranged in series containing a mixture of aqueous phosphoric acid (1N) and methanol (1:1). To check whether there was mass transfer from the first into the second wash bottle, deuterated aniline ( $680 \mathrm{ng}$ ) and $\mathrm{d}_{7}-2$-aminonaphthalene (606 ng) were added to the collecting solution of the first bottle. Results from the analysis of the contents of the two bottles after smoking one cigarette are listed in Table 5.

Only small amounts of amines are transferred into the 2nd bottle due to an optimum distribution of the mainstream smoke caused by the large surface glass frit. Hence, the sampling device can be reduced to one wash bottle. The small yield of the deuterated compounds added $\left(20 \%\right.$ in case of $d_{5}$-aniline, $30 \%$ in case of $d_{7}-2$ aminonaphthalene) was mainly caused by reactions with reactive smoke constituents rather than by enrichment losses. The concentrations of amines formed during the smoking process are significantly higher than those which have been actually measured and depend on the reactivity of the individual amines.

Model reaction to simulate the decomposition of amines during tobacco smoking

In order to quantify the reaction of aromatic amines with smoke constituents, the mainstream smoke from a mechanically smoked cigarette was passed into a wash bottle, an experiment replicated five times. To the collecting solution (1 $\mathrm{N}$ phosphoric acid + methanol, 7:3, $50 \mathrm{~mL}$ ) $\mathrm{d}_{5}$-aniline and $\mathrm{d}_{7}$-2-aminonaphthalene were added at the beginning of the experiment and the solution analyzed for the amines after the smoke from one cigarette had passed the wash bottles. The results of this experiment are presented in Table 6. On the basis of this and of further experiments it can be stated that the mainstream smoke from the type of cigarette used in this experiment contains about $20 \mathrm{ng}$ of 2-aminonaphthalene. Smoking of 3 cigarettes into the same wash bottle results in even smaller amounts of amines per cigarette. For instance, the yield of $d_{-}-2$-aminonaphthalene is reduced to about $20 \%$ of the amount actually added. This also holds for aniline.
Table 5.

Collection of mainstream smoke from a mechanically smoked cigarette by two wash bottles arranged in serles (ng/clg). Concentration related to fluoranthene; evaluation by GC/MS.

\begin{tabular}{|c|c|c|}
\hline & $\begin{array}{c}\text { Wash } \\
\text { bottle } 1\end{array}$ & $\begin{array}{l}\text { Wash } \\
\text { bottle } 2 \\
\end{array}$ \\
\hline Weighed Aniline- $d_{5}$ & 680.00 & 0.00 \\
\hline Aniline- $d_{5}$ & 137.01 & 0.15 \\
\hline Aniline & 74.66 & 4.88 \\
\hline o-Toluidine & 33.89 & 0.57 \\
\hline $\mathrm{m}$-Toluidine & 27.36 & 0.10 \\
\hline p-Toluidine & 17.09 & 3.17 \\
\hline 1-Aminonaphthalene & 14.65 & 0.07 \\
\hline 2-Aminobiphenyl & 4.17 & 0.09 \\
\hline Weighed d,-2-Amino- & 606.00 & 0.00 \\
\hline naphthalene & & \\
\hline$d_{\text {, }}$-Aminonaphthalene & 185.03 & 0.30 \\
\hline 2-Aminonaphthalene & 6.22 & 0.09 \\
\hline 4-Aminobiphenyl & 1.63 & $<0.20$ \\
\hline 2-Aminofluorene & 0.91 & $<0.13$ \\
\hline 3-Aminofluoranthene & 0.96 & $<0.08$ \\
\hline 1-Aminopyrene & 0.66 & $<0.09$ \\
\hline 6-Aminochrysene & 0.54 & $<0.06$ \\
\hline
\end{tabular}

Currently, the composition of the reactive smoke constituents can only be speculated. It became clear from preliminary experiments that the amine-degrading potency declined and finally completely disappeared after a couple of days in tobacco smoke condensate. An endpoint was reached after ca. 10 days, since reference standards were no longer destroyed.

Those findings suggest that adding larger amounts of a reactive amine to the collecting solution prior to the smoking process would at least partially intercept the reactive smoke constituents. The effect of p-toluidine in this respect is demonstrated in Table 7. It shows that significantly smaller amounts of amines are decomposed after the addition of $0.25 \mathrm{mg}$ of p-toluidine.

A comparison with Table 6 shows that various amines are decomposed to different extents.

An estimation of the amine mass originally formed by tobacco pyrolysis was only possible from the time of introducing the mainstream smoke into the collecting solutions onwards. By addition of weighed amounts of deuterated compounds (as internal standards) prior to passing the smoke into the wash bottle, it was possible to calculate the original mass of amines from the remaining amount of internal standard at the point of quantitation by $\mathrm{GC} / \mathrm{MS}$. 


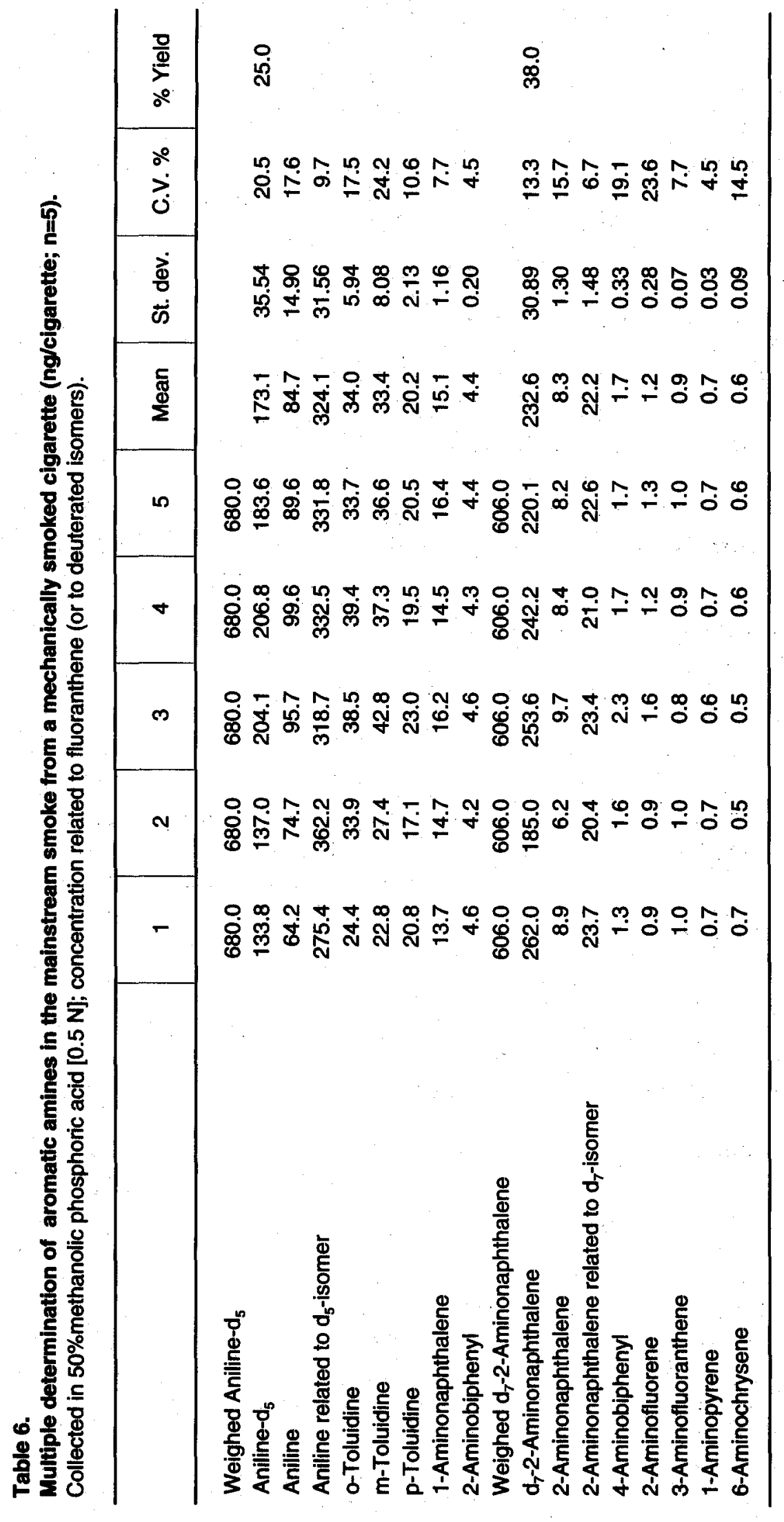




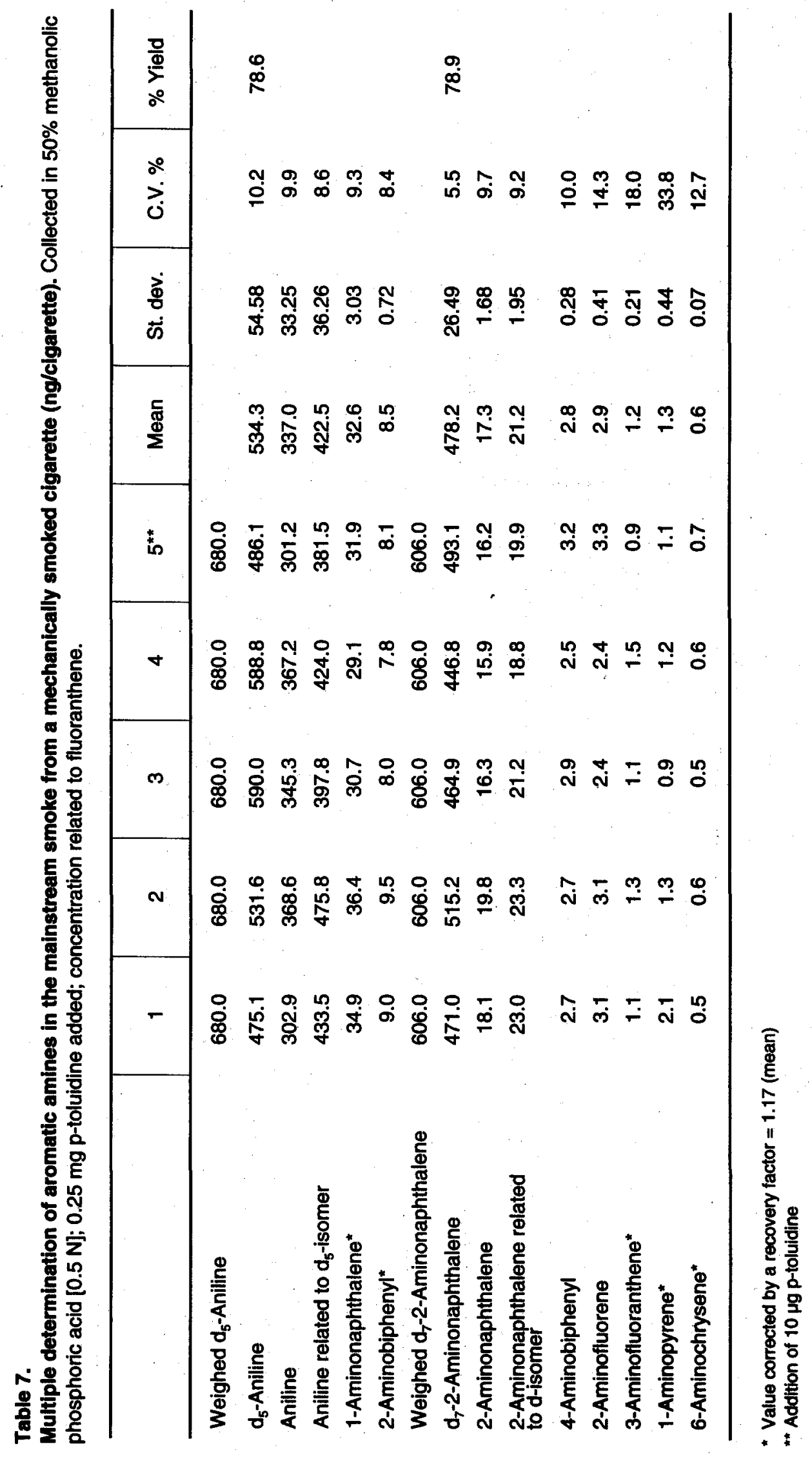




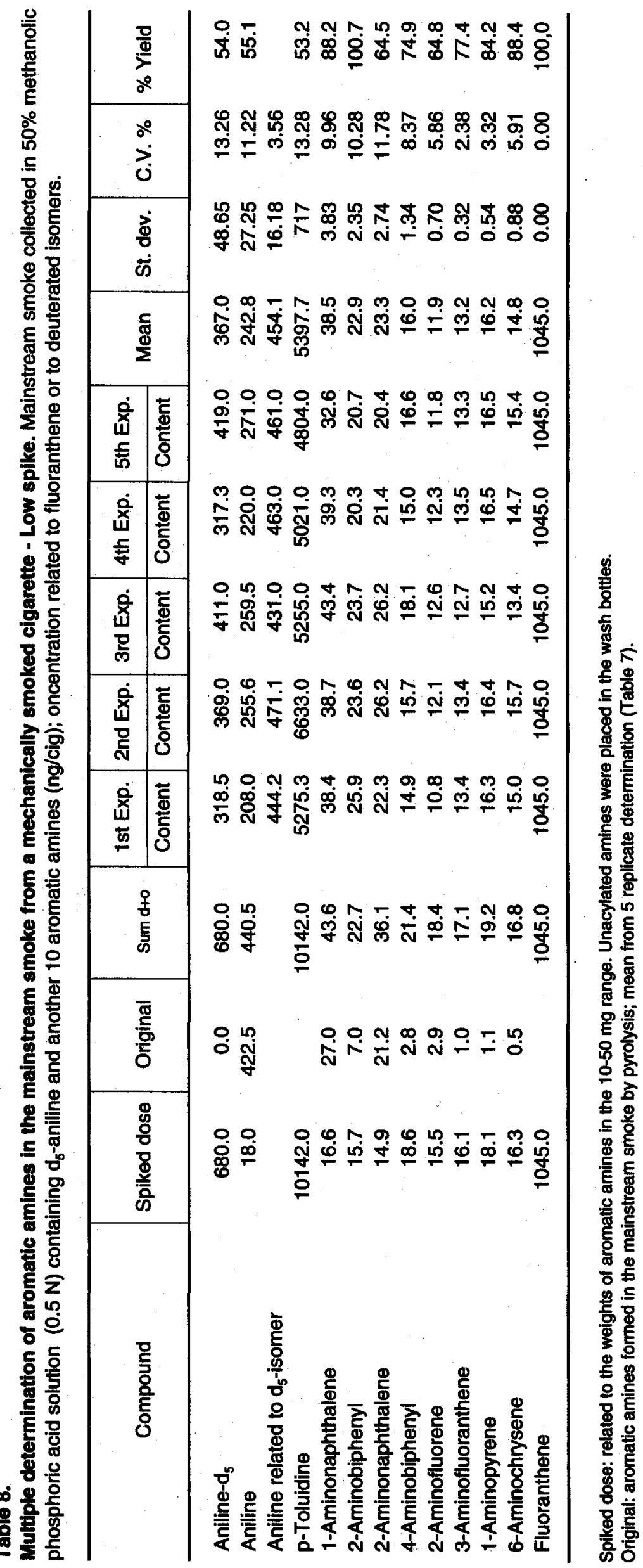




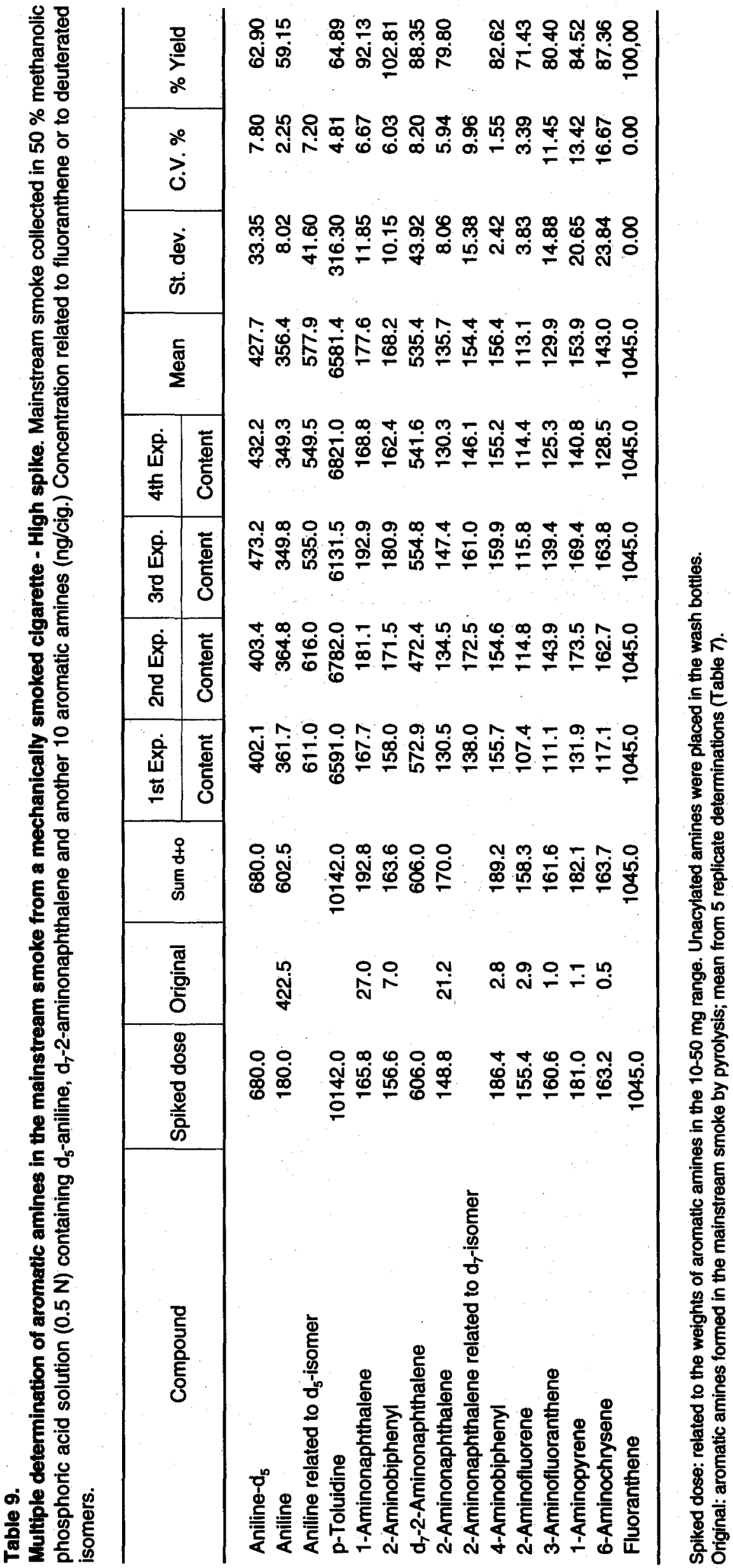


Only aniline, 2-aminonaphthalene and 4-aminobiphenyl were deuterated compounds commercially available or synthesized. Consequently, only the actual concentrations at the beginning of conducting mainstream smoke into the phosphoric acid solution could be determined.

Since it was not possible to synthesize other deuterated compounds, we attempted to estimate the original mass of other amines by adding unlabelled amines at the beginning of passing mainstream smoke into the collecting solution. We assumed, the collecting solution contained both the pure compounds added and amines present in the cigarette mainstream smoke - no decomposition reactions of the amines are presupposed. The results after addition of reference compounds as internal standards at two different concentrations are summarized in Table 8 and 9. Yields are related to the sum of spiked amines and amines formed during the smoking process (as given in Table 7).

In principle, the originally formed amine masses can readily be calculated from the yields determined. However, only in the case of those amines for which deuterated isomers have been added, is it possible to state the original mass. In general, the masses are underestimated especially in the case of amines which are readily decomposed. For the 2-aminonaphthalene the mass added is significantly greater than that formed, the yields actually found corresponded to losses caused by clean-up and decomposition. Hence, data obtained for smoking one cigarette have to be corrected by these factors. As may be seen from Table 9, yields of these amines are constant within the margin of error even when dosed 10 times higher.

There is presently no explanation for the high yield of $100 \%$ for 2-aminobiphenyl which should be about $10 \%$ lower. The high yield for 1-aminonaphthalene indicates that this compound is stable under the conditions applied and that it is not decomposed by other smoke constituents. The yield of $\mathbf{8 8 \%}$ obviously results from losses during the clean-up procedure. The low yields for 2aminonaphthalene, 4aminobiphenyl and 2-aminofluorene indicate a partial decomposition which could not be avoided by addition of large amounts of $p$-toluidine.

In comparison to blended cigarettes, the mainstream smoke of cigarettes made from alkaline tobacco contains significantly higher amounts of amines. Results from an investigation of a frequently smoked German and a French cigarette (without filters) and a blended cigarette (with filter) are compared in Table 10.
Table 10.

Comparative contents of aromatic amines in malnstream smoke of varlous mechanically smoked cigarettes (ng/clgarette) (collected in $50 \%$ methanolic phosphoric acid (0.5 N; $10 \mu \mathrm{p}$-Toluidine))

\begin{tabular}{|c|c|c|c|}
\hline & 1 & 2 & 3 \\
\hline Aniline* & 422.5 & 655.5 & 1549.4 \\
\hline o-Toluiding* & 240.1 & 337.0 & 938.0 \\
\hline m-Toluidine & 165.8 & 223.7 & 510.0 \\
\hline 1-Aminonaphthalene** & 31.6 & 56.9 & 77.0 \\
\hline 2-Aminobipheny| & 8.2 & 16.5 & 23.9 \\
\hline 2-Aminonaphthalene* & 21.2 & 33.4 & 53.6 \\
\hline 4-Aminobiphenyl* & 3.6 & 5.6 & 8.9 \\
\hline 2-Aminofluorene & 3.4 & 2.1 & 4.4 \\
\hline 3-Aminofluoranthene & 1.2 & 2.1 & 3.4 \\
\hline 1-Aminopyrene $\theta^{* *}$ & 1.3 & 2.4 & 2.5 \\
\hline 6-Aminochrysene** & 0.6 & 1.8 & 1.5 \\
\hline
\end{tabular}

1 = Blended cigarette with filter

2 = Cigarette made from alkaline tobacco without filter (Ger$\sim$ many)

3 = Cigarette made from alkaline tobacoo without filter (France)

Remarks:

* Values given for aniline, 2-aminonaphthalene and 4-aminobiphenyl have been corrected by recovery factors obtained from deuterated compounds.

Values for $\sigma$ and $m$-toluidine have been corrected by the recovery factor of $p$-toluidine.

* Values corrected by recovery tactors obtained from control analyses (taken from Table 9); mean = 1.17

\section{DISCUSSION}

The analytical procedure developed enables a realistic estimation of amine formation during the smoking process. The findings presented indicate that the aromatic amines formed are partially decomposed by reaction with other smoke constituents within a few minutes. Unfortunately, the reduction of the yield caused by this process can be minimized only after passing the smoke into the collecting phosphoric acid solution by addition of large amounts of p-toluidine. 
As mentioned above, the decomposition of the amines from their formation in the cigarette until their entry into the acidic collecting solution in the wash bottle - a distance of about $25 \mathrm{~cm}$ - cannot be measured. Varying the distance to $12 \mathrm{~cm}$ results in no significant differences. The suspicion is that the data reported in this paper are still too low.

Since a smoker may resorb the mainstream smoke immediately after its formation, an estimation of the originally formed amine masses is of essential importance for the evaluation of the hemoglobin adduct concentration and the urinary excretion of metabolites.

Concentrations of 2-aminonaphthalene $(21.2 \mathrm{ng} / \mathrm{cig}$.) and 4-aminobiphenyl ( $3.6 \mathrm{ng} / \mathrm{cig}$.) were found to be one order of magnitude higher using the intercept method described here than reported by LUCERI for the same blended cigarette (6).

As might be expected, smoking of cigarettes made of alkaline tobacco results in higher amine contents, e.g. 33 $\mathrm{ng}$ of 2-aminonaphthalene and $5.6 \mathrm{ng}$ of 4-aminobiphenyl per cigarette were found in this case.

\section{REFERENCES}

1. Pailer, M., Hübsch, W.J. and H. Kuhn: Fachliche Mitt. Oesterr. Tabakregie 7 (1967) 109).
2. Masuda, Y. and D. Hoffmann: Quantitative determination of 1-naphthylamine and 2-naphthylamine in cigarette smoke; Anal. Chem. 41 (1969) 650-652.

3. Schmeltz, I. and D. Hoffmann: Nitrogen-containing compounds in tobacco and tobacco smoke; Chem. Rev. 77 (1977) 295-311.

4. Patrianakos, C. and D. Hoffmann: Chemical studies on tobacco smoke; J. Anal. Toxicol. 3 (1979) 150-154.

5. Pieraccini, G., Luceri, F. and G. Moneti: New gaschromatographic/mass spectrometric method for the quantitative analysis of primary aromatic amines in main- and side-stream cigarette smoke $I$; Rapid Commun. Mass Spectrom. 6 (1992) 406-409.

6. Luceri, F., Pieraccini, G., Moneti, G. and P. Dolara: Primary aromatic amines from side-stream cigarette smoke are common contaminants of indoor air; Toxicol. Ind. Health 9 (1993) 405-413.

\section{Autbors' address}

Biochemisches Institut für Umweltcarcinogene,

Lurup 4,

D.22927 Großhansdorf. 